B O R I S G R O V

\title{
Modélisation analytique de l'action: Pareto versus Weber - Corrigendum
}

doi:Io.ror 7/Sooo3975607000392, Published by Cambridge University Press August 2007

In the English abstract on page 375, 'Parsonian' should be replaced with 'Paretian'.

The full English abstract should read as follows:

Today confronting Pareto versus Weber is commonplace. For the majority of contemporary researchers, validating one of the two theoretical constructs means ipso facto rejecting the other. The present paper attempts to prove the lack of scientific ground. The Weberian and Paretian approaches operate at two different levels. They should be put to work jointly in a sequential manner, Pareto first, Weber thereafter.

\section{$R E F E R E N C E$}

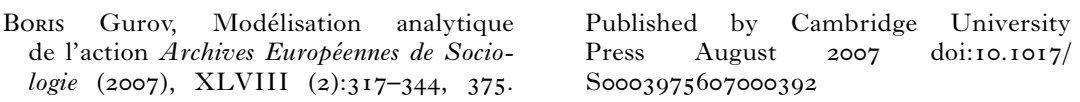

Boris Gurov, Université de Provence, Aix-Marseille-I, École Doctorale «Espaces, Cultures, Sociétés » [borisgurov@gmail.com].

Arch.europ.sociol., XLVIII, 2 (2007), EI-0003-9756/09/0000-862\$07.5 oper art +\$0.10 per page(C2009 A.E.S. 